\title{
Commercialisation of a Zimbabwean Government Department Challenges And opportunities For Human Resource Management
}

\author{
Sekai Noreen Gore \\ Lecturer, Faculty of Commerce and Law, Zimbabwe Open University, Harare, Zimbabwe
}

\begin{abstract}
Zimbabwe's public sector organisations have been on spotlight on performance related issues in the last two decades. Owing to new developments on the governance of public sector enterprises across the globe, with the rising need for governments to be held accountable for results, the Zimbabwean government engaged in various strategies to improve its performance. These have included the restructuring, privatisation and also commercialisation of some state-owned enterprises in an attempt to make them more effective. This research serves to analyse the commercialisation of Zimbabwe's Central Mechanical Equipment Department (CMED), which falls under the Ministry of Transport. The primary interest was to analyse the challenges and opportunities for HR as a result of the commercialisation, where it is believed that the commercialisation would change the senior management's expectations of HR in the organisation, and ultimately the role of the HR function in supporting corporate strategy, in an organisation whose mission now includes generating a profit. The research was largely influenced by postmodernism and was qualitative in nature. Its central argument is that any strategic change in an organisation provides opportunities and challenges for HR Practitioners to add value, and that this value addition of HR is influenced by its source of legitimacy in the organisation and the dominant values of the source. Using a sample of 45 employees in the organisation, who included 15 managerial employees (selected using purposive sampling method) and 30 non-managerial employees (selected using stratified random and simple random sampling methods), primary data was collected using semi-structured interviews for the former and self-administered questionnaires for the later. Secondary data was collected using company documents and other documents in the public domain. Findings reveal a lot of opportunities for HR to add value and demonstrate its value addition, particularly considering the profit orientation of the organisation and the positioning of the HR function in the organisation's structure. Challenges abound however, where there still remains some bureaucratisation of the organisation, and the influence of national politics in the operations of the entity. A conclusion is drawn to the effect that commercialisation creates a fertile ground for the practice of good HRM and demonstratable value addition.
\end{abstract}

Key Words:- Commercialisation, HR, Parastatals

\section{BACKGROUND TO THE STUDY}

The Zimbabwean Parliament passed a bill allowing the Central Mechanical Equipment Department to be commercialised in year 2000, following a declining service provision and the general failure to provide essential transport services to all government departments, ministries including the very important people (VVIP), who included the president, vice-presidents and ministers. This prompted the leadership of CMED to set a roadmap to improve the service delivery, by way of privatising the services of the government department. According to Statutory Instrument 186 of 2001 his Excellency the President of Zimbabwe in terms of paragraph (a) of subsection (1) of section 37 of interpretation Act (Chapter 1 : 01) 2001, assigned to the Minister of Transport and Communications the administration of the Central Mechanical Equipment Department (Commercialisation) Act 2000 (act no. 14 of 2000). The commercialisation of CMED was set out to make the firm more sustainable, without taking away its obligation to supply vehicles and equipment. Resultantly, although the department still remains accountable to the government, it no longer receives any money from the government budget treasury (Parliament of Zimbabwe 2000). Such a move towards commercialisation resulted in the Parastatal restructuring its business portfolio, to generate additional revenues. These included the business of fuels and lubricants, Easy-Go driving school, a car-hire service, reconditioning services and vehicle maintenance and repairs, among others. The main reason for commercialisation of Zimbabwean parastatals and state owned enterprises, including CMED, was and still is underperformance. In the year 2000 the Zimbabwe government decided to commercialise Central Mechanical Equipment Department for the following reasons (Hansards Parliament of Zimbabwe 2000);

1) Highly unsustainable debts owed by government ministries and departments, where before change of currency CMED had outstanding debts worth over four Zimbabwean billion dollars. It was not receiving 
revenue from the fiscus. Ministries with highest bills resorted to purchasing their own fleet by-passing CMED and the government allowed that to happen.

2) Corruption was eroding the operations of the department, resulting in poor service provisions, compounded by inconsistent distribution of vehicles and equipment, which was described as discriminatory.

3) Lack of a uniform approach to information trading within Zimbabwean government departments, Procurement Committee stopped using the vehicle replacement policies and procedures. This allowed the company to purchase all types of vehicles not suitable for the terrain and rough roads.

4) Attitudes to information provision, costing, pricing, and resourcing of information trading functions (Headroom Analysis Report, Lorimak Human Resource Consultancy (Pvt.) Ltd 2000).

Therefore high operating costs contributed and forced the Government to commercialise CMED. KPMG Consulting Inception Report of (2001) stated that, it was a priority to reduce accumulated debts in the government ministries and departments. The organization's viability went under great threat. CMED bills rose due to low vehicle and equipment hire charges and cost recovery in respect of vehicle accidents and repairs where a ministry or department was culpable (Zimbabwe Parliament 2000). Bills payable on demand to CMED by government ministries were being delayed for periods as long as six months. As a result of this CMED ended up being unable to manage its running costs as it was not operating effectively. There was no robust system for it to collect debts owed to the company such as the use of bill lifts (Zimbabwe Parliament 2000). More over human resources was not considered as first assets and production was generally low.

Efforts at the highest level in government to correct the situation failed due to a number of factors including budgetary limitations in the government portfolio as a whole. It was clear that the problem was attributed more to attitudes and behaviours than to any other reasons, in the absence of service-level agreements, because debtors were sister departments to CMED (Zimbabwe Parliament 2000).

According to Central Mechanical Equipment Department (Commercialization Act no. 14) of year 2000 the name Central Mechanical Equipment Department was changed to CMED (Pvt.) Ltd at the time of commercialisation. This posed challenges to external customers who were still sceptical about the entity, against their knowledge of its old culture and business ethics, which were generally bad and negatively affected performance. The name change was also associated with a consequent change in the mission of the new entity, to transcend beyond the traditional core business of providing vehicles and equipment to government ministries towards providing a service to public institutions, individuals and private companies (Parliament of Zimbabwe 2000). Consequently, according to CMED strategic plan document (2000), such a change of the status of CMED to a private company meant that employee status would change from being employed as civil servants to a new contract of employment based on a commercialised entity. This had legal implications in terms of the management of human resources, considering that traditionally, the employees of CMED were governed by the Public Service Act (Cap. 16.04) and now because there are in the private sector, by the Labour Act (Cap. 28.01) as amended. Arguably challenges do emerge in terms of human resource management, particularly when there is change in the business' strategic operation. These may involve matching and changing some of the human resources plans, policies, work ethos and philosophy, for example, in the case of CMED, to that of a private business which is profit orientated.

1.1 Research Aims

The main aim of the research was to analyse the challenges and opportunities for HR at the commercialised Zimbabwean entity, CMED. This would include the need to understand the circumstances leading to the commercialisation, the position and functions of HR prior to the commercialisation, with the aim to verify whether there were noticeable changes on corporate HR after the commercialisation, particularly with regards to the capacity of HR to add value, now that the mission of the organisation has changed. The research would also explore on the challenges faced by the HR department in managing this transition and thereafter.

1.2 Research Questions

1. What are the challenges that were faced during the transition?

2. What are the opportunities that came along with the transition?

\section{LITERATURE REVIEW}

Commercialisation has no universal definition. In the case of public sector institutions, it may be taken to include the transformation of a government department to an entity that provides or sells its goods and services to the public, with the aim of making a profit, and where the entity no longer relies on the fiscus for its operations. It should generate enough revenue to sustain itself, and where the organisation declares its dividends to Treasury. Beer (2001) regards it as part of strategic management decision that involves a government department being given the autonomy to trade as a private company yet be still accountable and owned by the government. The term commercialisation is at times used interchangeably with privatisation, even though the two are different. A private company declares its dividends through different approach, according to 
the Companies Act and is controlled by shareholders who are accountable for the company's losses and profits. In the latter example, when the government just commercialises the department, they maintain control and ownership of the institution.Commercialisation is not new, according to Buchanan and Huczynsiki (2003), considering that administratively, this same process of commercialisation was done in countries like Queensland where commercialisation was used by the government as a framework or process to deliver commercial activities or making their departments more profitable by introducing a new business strategy. This commercialisation initiative could be understood as a survival strategy to bail the ailing department from collapse. Hill and Myatt (2010) identified the adoption of various pricing strategies and introduction of new products to the market as common features of a commercialisation program that allows a government owned organisation to operate as a private entity. The choice of whether to commercialise or not is an outcome of various considerations. Research on public sector management has indicated the need for competitive governments that are accountable for results. This has resulted in governments adopting various strategies in order to improve their service delivery, under the broad umbrella term of New Public management. Choices would range from privatisation, to restructuring, to commercialisation. Common people challenges in these types of changes may include challenges of having to set targets, new jobs, conditions of service, job performance and human resource management systems (Mullins 2005). Jobs and job roles may also change, just as conditions of employment, and in many instances these are parallel to employee expectations. Such may require HR to transform the mind-sets of employees and also management, which again is not easy.

\section{METHODOLOGY}

The research was qualitative in nature, making an exploratory case analysis of one organisation, CMED. The research included a sample of 28 employees; 9 managerial employees, and 19 non-managerial employees, all of whom had an experience of working for CMED. Managerial employees were selected using purposive sampling and snowballing sampling methods. An example of snowballing may involve a circumstance where the director of finance can refer the researcher to the director of civil engineering. This would help reduce the "researcher effect" William (2001). Primary data was collected using interviews and selfadministered questionnaires. Interviews were held at the Head Office $(n=7)$, Provincial Offices $(n=2)$; that is, CMED Midlands and Mashonaland East provinces. Questionnaires were circulated and returned from two provinces, Mashonaland East $(n=10)$ and Midlands $(n=11)$. Secondary data was gathered using existing company documents such as company policies, staff manuals, strategic plans, and corporate strategies and human resources strategies, Hansard Reports and so on. Findings from interviews were recorded and analysed through the process of thematic analysis, by focusing on identifiable themes or patterns of behaviours and word used by the participants Baxter et al. (2008). According to Ofer (2007) thematic analysis is a process that could be used with most qualitative information as a way of seeing, making sense of related material, systematically observing situations, groups, organisations, interactions, cultures and behaviours.

\section{IV. $\quad$ FINDINGS AND DISCUSSION}

The commercialisation of CMED represents a strategy pursued by the government of Zimbabwe to decentralise public institutions and also make them competitive. Such a strategy of business restructuring also signifies a strategic change in an organisation, which also has been associated with a restructuring of business portfolio and cost re-alignment as the new entity now faces competition from the private sector. This represents a very fertile ground for HR to add value in the new establishment. The research sought to understand how the commercialisation of CMED created opportunities for HR and the challenges faced.

One of the intriguing findings in the research is that the perception by management of the role and value of the Human Resource Management function has not changed from their perception prior to the commercialisation. The department continues to be trapped by a number of policies that are far from being implemented.Challenges on human resource included the initiation of the organizational structure which would reduce it from 2,340 posts to less than 1, 000 posts.Commercialisation introduces transformation, culture change, and the required skills needed to compete in the market (Mintzberg 2001). Before commercialisation the provision of conditions of service like leave benefits, recruitment and selection, medical assistance and other benefits were centralised, that is they were being paid by the minister of Transport and Communications (Zimbabwe Parliament 2000). There was no human resource representative at the top management, which made it difficult for human resource needs to be represented. This possibly highlights the weakness of CMED management structure. (Director of Central Mechanical Equipment Department, Inception Report 22 August 2001.) The government took a strong course of action to deal with corruption which had rocked the department of Central Mechanical Equipment department by changing some of the top senior and middle management through commercialisation (Parliament of Zimbabwe 2000). Central Mechanical Equipment 
Department (Commercialisation) act no.14 of 2000. This way, the strategy becomes a reality (as plan, to achieve intended goals) and threats were found. The change of management here, was arguably meant to bring in new culture, beliefs, behaviours, attitudes and a different pattern of actions over time.

Researcher through investigation discovered that the workers behaviour and attitudes on inception of CMED (Pvt) Ltd changed favourably because they had good expectation of receiving good conditions of service. It was found that the company did not actually fulfil its promises. Most of the workers complained of lack of resources to keep the company operating properly. They were also affected of poor workmanship and human resources management. Their attitude towards work is deteriorating on daily basis, they need to be helped by senior management and human resource department.

Commercialisation of CMED has seen the control of the company by the board of directors and that has cut down bureaucracy in the process of promotion, recruitment and selection. There is a human resource board committee to examine the issues concerning staff grievances and conditions of service including staff welfare. The human resource department plan and initiate drafts of policies, procedures like the staff manuals for board's consideration. Board meetings are scheduled each week to consider the drafts and pass them to the main board meeting for scrutiny and ratification. This process is expeditiously executed by the board of directors to enable the effective operations of the company.

One of the major positive factors was the establishment of the post of Human Resource Executive (HRE) in the new structure. The HRE would represent workers at senior management level on issues such as; provision of staff welfare, health and safety, payment of salaries and wages, settlement of staff grievances and advisory role. This position used not to be on the establishment and workers did not have a fair representation at managerial level. This executive HR position changed the face of HR in the establishment. Structure is an asset in terms of political substance, and when corporate HR directly reports to the CEO, it is most likely to better influence bottom line as an advisor on people issues.

HR itself also faced challenges during and after the commercialisation process. One key challenge can be noted in terms of centralisation of corporate HR at the head office. This has been a common feature of public institutions in Zimbabwe; CMED included, and has affected the effective delivery of HR services by the organisation. The other challenges had to do with poor management response to employee concerns, as evidenced by delays in changing the organizational structure, salary and other benefits structure, policy on recruitment and selection, staff welfare and facilities, building a new culture and relationship between workers and management and defuse sectionalism among the employees and management, solving the previous problems brought forward from the government department, imparting the new regulations of the new company in the minds of the employees, challenges of failing to practise fair judgement on the cases committed by employees of the company, managing jobs and motivating employees and lack of financial resources for developing training and development programs.

Another HR challenge was that the government department had a centralised salary and benefits structure, where HR was not involved in the formulation of salary structures. These were supposed to be in line with the jobs, grade levels with the required notches to bridge the gaps on the grades. However, there were challenges where senior and junior employees were grouped together in one scale and the salary structure did not provide room for advancement within the salary scale. This is a big challenge to human resource department in the commercialised CMED which needs urgent attention to address the salary gaps of different grades such as artisans, clerks, transport hire officers and security officers because supervisory roles are compromised because of the poor grading system.

Salaries and benefits in the commercialised CMED for both employees and managers are indirectly controlled by a shareholder who is government which provides commencing salaries treated as minimum wage rates. Private sector utilizes National Employment Council (NEC) and commercialised CMED private limited uses Automotive Motor Industry rates for payment of its employee's wages and has a Cabinet policy which has a cap for management salaries and benefits. It was also observed that working hours and other conditions of service like the accrual of vacation leave, sick leave, and maternity leave are covered by the labour act (Chapter 28.01) of 1985. This allows the organization to oppress the workers whether the company have very high profits or not, management considers the agreed minimum wage published by (NEC) and the Cabinet.

A shattered recruitment and selection structure method used at the inception of CMED caused management to transfer poor performers and under-qualified employees from the government department to the commercialised CMED. In the absence of a clear staffing policy, many employees were selected with little or no regard to merit, but much to do with being in good standing.

The challenge of transforming mind-sets about the value of the HR function to other managers, against the traditional perceptions of HR was also a major blow in the company.

Managers are not willing to consult human resource department on various labour issues, including labour dispute management (comprising the administration of the code of conduct among others) because they feel HR lacks confidence and in depth knowledge on the policies and procedures surrounding employee conditions of 
service. This creates an opportunity for HR to demonstrate its value by way of developing themselves and line managers on those areas of people management such as labour relations. A lot of mistakes in the handling of disputes (for example, through wrongful and unfair dismissals) have increased litigation costs in the organisation, which could be avoided. Traditionally, there was limited accountability since the organisation was still directly under the armpit of government, but with the heightened increases on the need for HR to manage cost-efficiency and value addition, has become very significant.

Commercialised organization faces challenges on high costs paid on the poor work produced by human resource department, particularly due to improperly handled HRM issues. These include unfair labour practices, poor handling of grievances, health and safety issues. Most of these emanate from weak human resource management systems and not providing clear policies added by lack of communication to all the workers and management. This can be evidenced by many dismissed employees being reinstated with full benefits by the labour court, lost man-hours due to sickness, absenteeism, go-slows and related actions and also compensation acts. Health and Safety issues are not addressed by the human resource department resulting in employees injured on duty not paid benefits by National Social Security Authority (NSSA). The company has been issued a number of tickets and fines for not adhering to statutory instrument No.14 of which states that an injury on duty (IOD) must be reported to NSSA within 14 days from the day of injury of the worker while performing official duties. Some of these HR challenges, according to the respondents, would be quickly dealt with only if the organisation could employ a professional and experienced head of corporate HR to administer all the HR affairs of CMED Private Limited. The HR function should also be effectively devolved to line function in order to equip all management employees with the skills and knowledge of people management.

\section{RECCOMMENDATIONS}

Human resource department should be considered in the strategic plan of the company. The company should put in place a flat structure and reduce top heavy structure by having one general manager transport and equipment hire instead of current two employed, have one Finance Administration instead of two have a law officer employed as cooperate Executive to control the process of arbitration cases and advice on court procedures, reduce middle management positions to one by combining the responsibilities of financial accountant and management accountant and combining the responsibilities of Fuels manager and private transport hire and driver training Manager and have one position.

Human resource department should account for all staff welfare of the employees and receive total support from the managing director and senior managers. The department should take full charge of the establishment and implement the regulations used in the organization such as the labour act, the staff manual which was crafted by the company follow the sections as laid down. Workers should not be allowed to act in vacant positions for more than the stipulated time covered by the staff manual. Human resource department should address the welfare of the employees by producing a salary structure which separate junior and senior employees, clear carrier path for employees' succession plan to meet the expectations of both the company and employees, this will also develop the organization's objectives and programs.

We now know that there no job for life, and that multi - skilling is the way forward to develop employees but employees with good professional back ground should be encouraged to learn different jobs and add value to the organization like the commercialised CMED. The company in this type of environment with economic hardships should learn to equip its employees with different talents that they choose to develop their carrier path. Human resource should be active in the change management programs and liaise with other organizations to compare notes on human administration and worker representative organizations like the Trade Unions, labour officers, employment councils and senior management.

This suggests good public relations among interested parties in the human resource activities. Employees be allowed to join the trade unions of their choice and the company to join the Employers Management Council of Zimbabwe (EMCOZ) to provide its expertises and aspirations in the industry of their choice. The company should employ professional people as heads of departments to suit each division and enable the needs and objectives of the company to add value all the time. Employees should fit in this organization in line with the matching skills and experience in a commercialised CMED.

Ministry which is the shareholder should also by all means select board members with relevant qualifications and experience in different academic fields so that they advice the management with correct information. Those who managed the same organization before should not appointed again but be rotated to other companies to enable development of new skills, ideas to floor properly in the commercialised company. Human resource systems should be introduced in the commercialised CMED.

Top office of human resource department should have all the document pertaining to labour laws, National Social Security Act. Company act, environmental management act and Public Service Acts to enable speed solutions of staff quires. All senior and top management should be appointed on a three year contract 
basis renewable once only its period expires. This allows new ideas to be used by from new Chief Executive Officers from different organizations. A professional and experienced human resource executive should be considered together with others to fill the position of a Chief Executive Officer of the commercialised CMED whenever there is a vacancy. Challenges and opportunities which affected human resource division should not be concentrated on one department but should be shared among various divisions. In CMED as an organization challenges affecting the organization from top to bottom are caused by lack of unity. There are great opportunities in CMED Private Limited than the challenges which are in this case study caused by human error and can be avoided at all costs. Finally in conclusion, the nature of work done at CMED Private Limited is very repetitive, tedious and tiresome. The workshops should be improved by putting in place automation of service bays, loading and off loading of broken down vehicles, motor spares purchased in bulk and other materials kept in stores. Employees should be motivated by take home money not only relying on the NEC minimum wages. There should also be a rewarding scheme that recognises the performance achievers.

\section{BIBLIOGRAPHY}

[1] Anderson, D. Anderson L.(2001).Beyond Change Management .Advanced Strategies For Today's Transformational Leaders. Jossey-Bass.Usa.

[2] Armstrong M (2006), Handbook Of Human Resource Management Practice, $3^{\text {th }}$ Edition, $\quad$ Library Of Congress, London

[3] Armstrong. M. A (2006) Handbook Of Human Resource Management Practice (10th Edition). Kogan Page , London

[4] Beer , M.(2001). How To Develop An Organisation Capable Of Sustained High Performance. Embrace The Drive For Results-Capability Development Paradox. Organisational Dynamics.29 (4).233-247

[5] Beer, M., Spector, B., Lawrence, P., Quinn Mills, D. \& Walton, R. (1984) Managing Human Assets. The Free Press: New York.

[6] Bogan, C.E. And M.J English (1994), Benchmarking For Best Practices: Winning Through

[7] Buchanan, D. \& Huczynski, A. (2003). Organisational Behaviour: An Introductory Text. Ft PrenticeHall.London

[8] Cohen L Et Al (1994) Research Methods In Education $4^{\text {th }}$ Edition, Routeledge, London

[9] Darren. M (2007) Hard Is Soft. Exploring The Dangers Of The Hard And Soft Distinction. International Journal Of Information Systems And Change Management .2(1):4-20

[10] Dibb, S. Et Al. (2001): Marketing - Concepts And Strategies; Fourth European.Edition.Houghton Mifflin; Boston

[11] Dooley D. (2003), Social Research Methods, Prentice Hall, New Delhi.

[12] Drucker, P.F. (2005).The Frontiers Of Management: Where Tomorrow's Decisions Are Being Shaped Today. London: Heinemann.

[13] Dyer, L And Revees (1995) Studying Human Resource Strategy: An Approach And An Agenda, Prentice Hall, New York

[14] Fombrun, C. J., Tichy, N. M. \& Devana, M .A. (1984) Strategic Human Resource Management. Wiley: New York. 